\title{
Idiopathic systemic capillary leak syndrome in childhood: A Literature Review
}

\author{
Tu-Anh Tran ${ }^{1 *}$, Anne Filleron', Mathieu Simonin ${ }^{2}$ and Pierre Corbeau ${ }^{3}$ \\ 'Department of Pediatrics, Nîmes University Hospital, INSERM U 1 183, Montpellier-Nîmes University, Nîmes, France \\ ${ }^{2}$ Institut Gustave Roussy, Department of Pediatric Oncology, 114 Rue Paul Vaillant, 94800 Villejuif, France \\ ${ }^{3}$ Department of Immunology, Nîmes university hospital, Montpellier-Nîmes university, Nîmes, France
}

Article Info

\section{Article Notes}

Received: October 24, 2016

Accepted: January 14, 2017

\section{*Correspondence:}

Tu-Anh Tran, Department of Pediatrics, Nîmes University Hospital, 1 place Robert Debré, 30029 Nîmes, France. Tel: +33 4666832 84, E-mail: tu.anh.tran@chu-nimes.fr.

( 2016 Tran T. This article is distributed under the terms of the Creative Commons Attribution 4.0 International License.

\section{Keywords}

Systemic capillary leak syndrome

Children

Clarkson's disease

Review

Pediatric

Physiopathology

Cytokines

\section{ABSTRACT}

Systemic capillary leak syndrome (SCLS), is a rare condition characterized by a recurrent stereotypical triad: hypovolemic shock, generalized edema, paradoxical hemoconcentration and hypoalbuminemia. It is caused by massive fluid extravasation into the interstitial space. Mortality may result from hemodynamic failure in the acute phase or cardiac failure due to reflex circulatory overload in the sub-acute phase. To date, twenty-one pediatric cases were reported in the literature. Sex ratio (M/F) was 0.32 with a median age at disease onset of 5.7 years and at diagnosis of 6 years. The disease was recurrent in $81 \%$ of patients with a median of three attacks. Severe complications were possible involving central nervous system $(n=2)$ or rhabdomyolysis, with a compartment syndrome needing fasciotomy $(n=5)$. The median time to clinical recovery was five days. Although the clinical manifestations of pediatric and adult SCLS were similar; in the opposite of adult SCLS, none of the children showed evidence of monoclonal gammopathy and three pediatric cases had a family history of SCLS. Seventy five percent of the patients were treated with prophylactic treatment (mainly immunoglobulins, theophylline plus verapamil). Several inflammatory cytokines were suspected to be involved in the pathophysiology of SCLS, especially interleukin-17 and tumor necrosis factor -alpha.

\section{Introduction}

Systemic capillary leak syndrome (SCLS), also known as Clarkson's disease ${ }^{1}$, is a rare and severe condition characterized by a recurrent stereotypical triad: hypovolemic shock, generalized edema, paradoxical hemoconcentration and hypoalbuminemia ${ }^{2}$. It is caused by massive fluid extravasation into the interstitial space. Mortality may result from hemodynamic failure in the acute phase or cardiac failure due to reflex circulatory overload in the subacute phase ${ }^{3}$. The physiopathology of this disease is still debated. Yet, studies clearly describe an inflammatory substratum ${ }^{4,5}$, and we have recently shown that interleukin-17 might be involved ${ }^{6}$. Approximately 170 idiopathic systemic capillary leak syndromes have been reported in the literature ${ }^{7}$. Here we review all the 21 published cases of pediatric idiopathic SCLS.

\section{Review of the literature}

We conducted a literature search to identify case reports of pediatric ( $<18$ years) idiopathic SCLS. Briefly, PubMed was searched from January 1960 to October 2016 using the following keywords: "idiopathic capillary leak syndrome", "Clarkson's disease”, "pediatric 
idiopathic capillary leak syndrome", "pediatric Clarkson's disease". Among the 178 eligible articles, we finally selected 21 cases for further analysis ${ }^{6,8-22}$ after exclusion of the adult patients.

The sex ratio (M/F) of pediatric cases was 0.32 with a median age at disease onset of 5.7 years (range: 17 days-17 years) and a median age at diagnosis of 6.0 years (range: 17 days-23 years). Three cases had a family history of SCLS. Individual characteristics and disease courses are summarized in Table 1. Four patients had only one attack, whereas the others experienced several ones with a median of three attacks (Table 1). A possible viral infection was suspected as a triggering factor for 11 patients (Table 1). Prodromal symptoms occurred in 17 patients, including flu-like symptoms in nine patients and gastrointestinal symptoms in nine patients (Table 1). Sixteen patients presented with edema (periorbital, facial, limbs, or generalized ascites) and among 16 patients who experienced hypotension, ten presented with hypovolemic shock. In addition, five patients had heart failure and a further six developed pulmonary edema during the recovery phase (Table 1). Two patients suffered from neurological complications (cerebellar edema or seizure) (Table 1).

Rhabdomyolysis was found in eight patients (Table 1). Five of them presented with a compartment syndrome and fasciotomy was necessary in five patients (Table 1). The median time to clinical recovery was five days (range: 1-27 days). Three patients ${ }^{6,14,19}$ had biopsies (muscular or cutaneous), both showing non-specific abnormalities. C1

\begin{tabular}{|c|c|c|c|c|c|c|c|c|c|c|c|}
\hline & Reference & Sex & $\begin{array}{l}\text { Age at } \\
\text { onset }\end{array}$ & $\begin{array}{c}\text { Age at } \\
\text { diagnosis }\end{array}$ & Attacks (n) & Prodroma & Trigger & Complications & $\begin{array}{l}\text { Biological } \\
\text { features }\end{array}$ & $\begin{array}{c}\text { SCLS family } \\
\text { history }\end{array}$ & $\begin{array}{l}\text { Time } \\
\text { to recovery }\end{array}$ \\
\hline 1 & Luquel $^{8}$ & $\mathrm{M}$ & $17 y$ & $23 y$ & 3 & No & Season & APE & NA & Sister & 24 hours \\
\hline 2 & Foeldvari $^{9}$ & $\mathrm{~F}$ & $3 y$ & $9 y$ & 5 & $\mathrm{AbP}$ & URTI & No & $N A^{a}$ & No & $2 d$ \\
\hline 3 & Karatzios $^{10}$ & $\mathrm{~F}$ & $6 y$ & $6.8 \mathrm{y}$ & 2 & $\mathrm{AbP}$ & Influenzae (H3N2) & Cpt Sd & NA & No & 24 hours \\
\hline 4 & Onal $^{11}$ & $\mathrm{~F}$ & $3 w$ & $5 \mathrm{~m}$ & 3 & Diarrhoea & Diarrhoea & No & ARI & No & $27 d$ \\
\hline 5 & Dowden $^{12}$ & $\mathrm{M}$ & $6 y$ & $6 y$ & 1 & $\begin{array}{l}\text { Fever, Nausea, } \\
\text { Vomiting }\end{array}$ & No & Cpt Sd & $\begin{array}{l}\text { ARI, RM, } \\
\text { IL-6/TNF }\end{array}$ & No & $5 d$ \\
\hline 6 & Kapoor $^{13}$ & NA & NA & $4 y$ & NA & NA & NA & NA & NA & No & NA \\
\hline 7 & Kapoor $^{13}$ & NA & $17 d$ & $17 \mathrm{~d}$ & NA & NA & NA & NA & NA & Mother & NA \\
\hline 8 & $\begin{array}{l}\text { Sion-Sar- } \\
\text { id }^{14}\end{array}$ & $\mathrm{M}$ & $5 \mathrm{~m}$ & $8 y$ & 5 & AbP, Vomiting & No & $\begin{array}{c}\text { APE, Heart } \\
\text { failure, PRES } \\
\text { Sd }\end{array}$ & ARI, RM & $\begin{array}{l}8 \text { family } \\
\text { cases }\end{array}$ & $7 d$ \\
\hline 9 & Gousseff $^{15}$ & $\mathrm{~F}$ & $5.4 \mathrm{y}$ & $5.7 y$ & 4 & NA & NA & NA & NA & No & NA \\
\hline 10 & Piastra $^{16}$ & $\mathrm{~F}$ & $6 y$ & $6 y$ & 2 & Fever & No & No & ARI, RM & No & $7 d$ \\
\hline 11 & Milani $^{17}$ & $\mathrm{~F}$ & $34 \mathrm{~m}$ & $48 \mathrm{~m}$ & 4 & Fever, Cough & URTI & Cpt Sd & $\mathrm{ARI}, \mathrm{RM}$ & No & NA \\
\hline 12 & Iwasa $^{18}$ & $\mathrm{~F}$ & $10 y$ & $10 y$ & 2 & AbP, diarrhea & No & Cpt Sd & $\begin{array}{l}\text { ARI, RM,G- } \\
\text { CSF/IL-6 }\end{array}$ & No & $3 d$ \\
\hline 13 & Perme $^{19}$ & $\mathrm{M}$ & $8 y$ & $9 y$ & 2 & $\begin{array}{c}\text { Coryzal symp- } \\
\text { toms, Cough, } \\
\text { Fever }\end{array}$ & Influenzae A & Heart failure & ARI, RM & No & $7 d$ \\
\hline 14 & $\mathrm{Hsu}^{20}$ & $\mathrm{M}$ & $8 y$ & $8 y$ & 1 & $\begin{array}{l}\text { Coryzal symp- } \\
\text { toms, Vomiting }\end{array}$ & $\begin{array}{c}\text { Rhinovirus, } \\
\text { Para-influenza } 3\end{array}$ & APE & $N A^{a}$ & No & $4 d$ \\
\hline 15 & $\mathrm{Hsu}^{20}$ & $\mathrm{~F}$ & $22 \mathrm{~m}$ & $22 \mathrm{~m}$ & 3 & $\begin{array}{l}\text { Coryzal symp- } \\
\text { toms }\end{array}$ & $\begin{array}{c}\text { Respiratory Synci- } \\
\text { tial Virus }\end{array}$ & APE & $\mathrm{RM}^{\mathrm{a}}$ & No & NA \\
\hline 16 & $\mathrm{Hsu}^{20}$ & $\mathrm{~F}$ & $6 y$ & $10 y$ & 2 & $\begin{array}{l}\text { Coryzal symp- } \\
\text { toms }\end{array}$ & Influenzae A & Cpt Sd & $\mathrm{RM}^{\mathrm{a}}$ & No & NA \\
\hline 17 & $\mathrm{Hsu}^{20}$ & $\mathrm{~F}$ & $3 y$ & $6 y$ & 3 & $\begin{array}{l}\text { Coryzal symp- } \\
\text { toms, Diarrhea }\end{array}$ & Streptococcus A & APE & $N A^{a}$ & No & NA \\
\hline 18 & $\mathrm{Hsu}^{20}$ & $\mathrm{M}$ & $4 y$ & $4 y$ & 3 & $\begin{array}{c}\text { Coryzal symp- } \\
\text { toms, Vomiting, } \\
\text { Diarrhea }\end{array}$ & Influenzae A & Heart failure & $N A^{a}$ & No & NA \\
\hline 19 & Kerketta $^{21}$ & $\mathrm{~F}$ & $6 y$ & $6 y$ & 3 & No & No & No & NA & No & $8 d$ \\
\hline 20 & Simonin $^{6}$ & $\mathrm{~F}$ & $11.5 y$ & $11.5 \mathrm{y}$ & 1 & $\begin{array}{l}\text { Myalgia, Ar- } \\
\text { thralgia, Fever }\end{array}$ & URTI & APE, Seizure & $\begin{array}{l}\text { ARI, TNF/ } \\
\text { IL-17 }\end{array}$ & No & $5 d$ \\
\hline 21 & Moreira $^{22}$ & $\mathrm{~F}$ & $5 y$ & $5 y$ & 1 & Vomiting & No & APE & NA & No & NA \\
\hline
\end{tabular}

Abbreviations: y: years, m: months, w: weeks, d: days; AbP: Abdominal pain, APE: acute pulmonary edema, ARI: acute renal impairment, Cpt Sd: compartment syndrome, NA: not available, PRES syndrome: Posterior Reversible Encephalopathy syndrome, RM: Rhabdomyolysis, SCLS: Systemic Capillary Leak Syndrome, Sd: syndrome, URTI: Upper Respiratory Tract Infection. ${ }^{a} 4$ of this 6 cases have an increase of TNF.

Table 1. Physical and biological features of the paediatric idiopathic SCLS cases. 
esterase inhibitor was normal when analyzed, while the inflammatory marker tumor necrosis factor (TNF)-alpha was high in six cases ${ }^{6,12,20}$, and interleukin-17 in one case ${ }^{6}$. Surprisingly, none of the 15 children whose data were available showed evidence of the monoclonal gammopathy that is otherwise frequently seen in adult SCLS.

Therapy during the acute phase included massive intravenous fluid administration in all cases. Fluid administration led to severe complications during the repletion phase: seven patients suffered acute pulmonary edema and three patients presented with heart failure (Table 1). Inotropic drugs and/or mechanical ventilation were necessary in ten cases, intravenous or subcutaneous immunoglobulins and/or systemic steroids in eight cases, and anti-TNF therapy in one case ${ }^{12}$. After the attack, 12 patients received one or more prophylactic treatments: Gingko biloba alone $(\mathrm{n}=1)^{8}$ or associated with terbutaline $(n=1)^{11}$, theophylline with terbutaline $(n=4)^{9,12,18,21}$, montelukast $(\mathrm{n}=1)^{13}$, verapamil and aminophylline $(\mathrm{n}=1)^{17}$ and immunoglobulins $(\mathrm{n}=4)^{20}$. Two deaths were reported: one occurred 2.7 years after the first attack ${ }^{15}$, one in a 17-day-old baby during his first attack ${ }^{13}$. No one of the patients who died was on prophylactic treatment.

\section{Discussion}

The clinical and laboratory features of pediatric disease are highly similar to adult cases ${ }^{13,15}$, except for two important differences. Firstly, monoclonal gammopathy has not been reported in the pediatric setting, in striking contrast to the high incidence $\left(89 \%{ }^{15}\right.$ or $\left.76 \%{ }^{13}\right)$ observed in adult patients. The contribution of gammopathy to disease pathogenesis remains debated ${ }^{23}$. Also, we have found no evidence that gammopathy has any correlation with SCLS in children. Secondly, the occasional family history of SCLS in pediatric cases has not been reported in adults ${ }^{13,15}$, suggesting that an inherited predisposition confers a higher risk of earlier presentation.

Neurologic involvement has been reported in only three adults ${ }^{24}$ and in two pediatric cases thus far. SionSarid et $\mathrm{al}^{14}$. reported a case of SCLS with neurological complications. In their case, the clinical and the radiological findings were similar to those of reversible posterior leukoencephalopathy syndrome, an uncommon neurologic syndrome, after rapid onset of severe hypertension. In our case previously reported ${ }^{6}$, hyponatremia present during the acute phase could be partly responsible for a degree of brain edema and seizures. However, the origin of the CNS-abnormality remains unknown in our case. In both cases, the neurologic deficits and the MRI brain lesions completely resolved.

Therapy during the acute phase consists in fluid administration to stabilize hemodynamic instability. However, this fluid replacement should not be excessive because some patients affected with SCLS die due to complications of massive fluid repletion (acute pulmonary edema and/or heart failure).

Elevated inflammatory cytokines have been reported in patient's sera ${ }^{20}$. Remission samples of our patient's leukocytes exhibited abnormal patterns of cytokine secretion as levels of Th17 pro-inflammatory factors in supernatants of cultured PBMC were elevated compared to healthy controls $s^{6}$. Strikingly, these differences were more marked following in vitro leukocyte stimulation, suggesting that intrinsic differences in cytokine responses to biological stimuli in vivo might contribute to disease pathogenesis.

\section{Conclusion}

SCLS remains a rare disease in children but with increasing number of cases recently reported. Due to the extremely low incidence of pediatric SCLS, recommendation for treatment and pathophysiology studies might be better undertaken within the framework of an international registry.

\section{Acknowledgments}

Thanks are extended to Drs Mariella Lomma and Carey Suehs for editing the manuscript.

\section{References}

1. Clarkson B, Thompson D, Horwith M, et al. Cyclical edema and shock due to increased capillary permeability. Am J Med. 1960; 29: 193-216.

2. Takabatake T. Systemic capillary leak syndrome. Intern Med. 2002; 41: 909-10.

3. Sanghavi R, Aneman A, Parr M, et al. Systemic capillary leak syndrome associated with compartment syndrome and rhabdomyolysis. Anaesth Intensive Care. 2006; 34: 388-91.

4. Xie Z, Chan E, Yin Y. Inflammatory Markers of the Systemic Capillary Leak Syndrome (Clarkson Disease). J Clin Cell Immunol. 2014; 5: 1000213.

5. Xie Z, Ghosh CC, Patel R. Vascular endothelial hyperpermeability induces the clinical symptoms of Clarkson disease (the systemic capillary leak syndrome). Blood. 2012; 119: 4321-32.

6. Simonin M, Corbeau P, Durand P. A possible role for IL-17 in Clarkson's disease. Eur J Paediatr Neurol. 2016; 20: 953-6.

7. Wells AU, Kokosi M, Karagiannis K. Treatment strategies for idiopathic interstitial pneumonias. Curr Opin Pulm Med. 2014; 20: 442-8.

8. Luquel L, Glaser E, Canuel C, et al. Capillary hyperpermeability An uncommon cause of hypovolemic shock. Rev Med Interne. 1989; 10: 359-60.

9. Foeldvari I, Waida E, Junker AK. Systemic capillary leak syndrome in a child. J Pediatr. 1995; 127: 739-41.

10. Karatzios C, Gauvin F, Egerszegi EP. Systemic capillary leak syndrome presenting as recurrent shock. Pediatr Crit Care Med. 2006; 7: 377-9.

11. Onal H, Aktuglu-Zeybek C, Altun G. Capillary leak syndrome in a 5-month-old infant associated with intractable diarrhoea. Ann Trop Paediatr. 2007; 27: 81-6.

12. Dowden AM, Rullo OJ, Aziz N. Idiopathic systemic capillary leak syndrome novel therapy for acute attacks. J Allergy Clin Immunol. 2009; 124: 1111-3. 
13. Kapoor P, Greipp PT, Schaefer EW. Idiopathic systemic capillary leak syndrome (Clarkson's disease) the Mayo clinic experience. Mayo Clin Proc. 2010; 85: 905-12.

14. Sion-Sarid R, Lerman-Sagie T, Blumkin L. Neurologic involvement in a child with systemic capillary leak syndrome. Pediatrics. 2010; 125 : e687-92.

15. Gousseff M, Arnaud L, Lambert M. The systemic capillary leak syndrome a case series of 28 patients from a European registry. Ann Intern Med. 2011; 154: 464-71.

16. Piastra M, Pietrini D, Conti G, et al. Sudden shock from capillary leak. Lancet. 2012; 379: 976.

17. Milani GP, Dellepiane RM, Castellazzi ML, et al. Episodic idiopathic systemic capillary leak syndrome in a girl. Pediatr Int. 2013; 55: e812.

18. Iwasa T, Ohashi H, Kihira K, et al. 10-year-old girl with life-threatening idiopathic systemic capillary leak syndrome: a case report. BMC Pediatr. 2014; 14: 137.
19. Perme T, Pokorn M, Markelj G, et al. Two episodes of systemic capillary leak syndrome in an 8-year-old boy, following influenza A virus infection. Pediatr Infect Dis J. 2014; 33: 222-4.

20. Hsu P, Xie Z, Frith K, et al. Idiopathic systemic capillary leak syndrome in children. Pediatrics. 2015; 135: e730-5.

21. Kerketta J, Lodh M, Mandal K. Clarkson disease systemic capillary leak syndrome in a 6-year-old girl case report. Paediatr Int Child Health. 2015; 35: 160-3.

22. Moreira DC, Ng CJ, Quinones R, et al. Microangiopathic Hemolytic Anemia Due to ADAMTS-13 Loss in Idiopathic Systemic Capillary Leak Syndrome. J Thromb Haemost. 2016.

23. Atkinson JP, Waldmann TA, Stein SF, et al. Systemic capillary leak syndrome and monoclonal IgG gammopathy studies in a sixth patient and a review of the literature. Medicine (Baltimore). 1977; 56: 22539.

24. Bertorini TE, Gelfand MS, O'Brien TF. Encephalopathy due to capillary leak syndrome. South Med J. 1997; 90: 1060-2. 